\title{
Influence of Microstructure and Chemical Composition on Microhardness and Wear Properties of Laser Borided Monel 400
}

\author{
Mateusz Kukliński ${ }^{1}$, Aneta Bartkowska ${ }^{2}$, Damian Przestacki ${ }^{1, *}$ (이 and Grzegorz Kinal ${ }^{3}$ \\ 1 Faculty of Mechanical Engineering, Institute of Mechanical Technology, Poznan University of Technology, \\ ul. Piotrowo 3, 61-138 Poznan, Poland; mateusz.kuklinski@doctorate.put.poznan.pl \\ 2 Faculty of Materials Engineering and Technical Physics, Institute of Materials Science and Engineering, \\ Poznan University of Technology, ul. Jana Pawła II 24, 61-138 Poznan, Poland; \\ aneta.bartkowska@put.poznan.pl \\ 3 Faculty of Civil and Transport Engineering, Institute of Machines and Motor Vehicles, Poznan University of \\ Technology, Piotrowo 3, 61-138 Poznan, Poland; grzegorz.kinal@put.poznan.pl \\ * Correspondence: damian.przestacki@put.poznan.pl
}

Received: 10 November 2020; Accepted: 15 December 2020; Published: 16 December 2020

\begin{abstract}
In this study, wear properties of Monel 400 after laser alloying with boron are described. Surfaces were prepared by covering them with boron paste layers of two different thicknesses $(100 \mu \mathrm{m}$ and $200 \mu \mathrm{m})$ and re-melting using diode laser. Laser beam power density was equal to $178.3 \mathrm{~kW} / \mathrm{cm}^{2}$. Two laser beam scanning velocities were chosen for the process: $5 \mathrm{~m} / \mathrm{min}$ and $50 \mathrm{~m} / \mathrm{min}$. Surfaces alloyed with boron were investigated in terms of wear resistance, and the surface of untreated Monel 400 was examined for comparison. Wear tests were performed using counterspecimen made from steel $100 \mathrm{Cr} 6$ and water as a lubricant. Both quantitative and qualitative analysis of surfaces after wear test are described in this paper. Additionally, microstructures and properties of obtained laser alloyed surfaces are presented. It was found that the wear resistance increased from four to tens of times, depending on parameters of the laser boriding process. The wear mechanism was mainly adhesive for surfaces alloyed with initial boron layer $100 \mu \mathrm{m}$ thick and evolves to abrasive with increasing boron content and laser beam scanning velocity. Iron particles detached from counterspecimens were detected on each borided surface after the wear test, and it was found that the harder the surface the less built-ups are present. Moreover, adhered iron particles oxidized during the wear test.
\end{abstract}

Keywords: Monel 400; laser heat treatment; laser boriding; diode laser; wear resistance; wear mechanism

\section{Introduction}

Nowadays, non-ferrous alloys have an increasingly important role in industry and their properties are often modified with high-energy heat sources like laser beam [1-3]. Laser processes, including laser alloying [4-6] and laser remelting [3] are increasingly displacing plasma processes [7] due to the fact that quality and properties of obtained layers are promising. Monel 400, which was laser treated in this study, is a one-phase nickel-copper alloy. Its main advantage is high corrosion resistance. Thus, this alloy is generally applied in harsh environments, including seawater, alkalis, salts or acids. The main industries in which parts made from Monel 400 are present (as valves, pumps and tanks) are marine engineering and chemical processing [8-10]. On the other hand, the main disadvantage of Monel 400 is its relatively low hardness in comparison with other nickel alloys [11]. Taking into consideration that products made from this material are often exposed to high flow rates, there is a risk of failures due to erosion, cavitation or wear. 
Wear of materials generates high production costs and thus it is often a research object in materials engineering [12]. Due to a high risk of wearing parts made from Monel, tribological behavior of this alloy has been the subject of research for at least 50 years. In 1973, Bill reported that wear mechanism of Monel 400 alloy is initially adhesive with plastic deformation and the next stage of wear is an oxidation process occurring on the surface [13]. Nowadays researchers focus on investigating wear of Monel 400 in different states and environments. In 2016, Esgin et al. examined wear properties of different Monel alloys produced with powder metallurgy. It was found that mass loss during the wear test under the same conditions was the highest for Monel 400 alloy. Moreover, only this alloy suffered adhesive wear during the process [14]. In 2018, Ma et al., investigated tribocorossion behavior of Monel 400 in artificial seawater with different loads applied during the wear test. Regardless of the load, small regions of loose corrosion were found on surfaces after the wear test and it was found that the wear was the dominant factor in the corrosive wear process. Moreover, abrasive wear occurred in each experiment [15]. In 2019, Waliszyn and Adamkiewicz investigated Monel 400 erosive wear under the influence of hydraulic cavitation. They found that (in these conditions) proneness to erosive damage of this Ni-Cu alloy is between pure nickel and steel C45 which means relatively poor wear resistance [16].

Low wear resistance of Monel 400 means improvements should be made to the tribological properties of its surface. One of the processes which increases hardness and thus wear resistance of nickel alloys is boriding. Researchers have been describing effects of alloying nickel and its alloys with boron for about two decades. In 2000, Ueda et al. borided surface of pure nickel with powder-pack method. The process resulted in increasing surface hardness about six times and significantly improved wear resistance [17]. After this successful attempt, researchers continued studies, working on new substrate materials and methods for improving tribological properties by boron alloying. For this purpose, Anthymidis et al. borided pure nickel in a fluidized bed reactor. As a result, produced coatings showed an approximately 50\% increase in resistance to wear compared to the untreated nickel [18]. In further studies, it was found that boriding is an effective method of improving surface properties of nickel alloys as well. In 2008, Petrova et al. investigated effects of boriding alloys for automotive applications including Inconel 625 and Inconel 718. Microhardness increased six and four times respectively after the process [19]. In this study the comparison of wear resistance between treated and untreated surfaces was not considered, however, five years later, Sista et al. borided Inconel 600 electrochemically, resulting in 8 to 10 times increase in microhardness and examined the wear resistance. It was found that the wear volume dropped more than 40 times due to alloying surface with boron [20]. In 2017, Gunen et al. confirmed these results on Inconel 625 by obtaining improved wear resistance by boriding [21] and borotitanizing [22]. In 2019, Silva et al. reported similar results for Inconel 718 [23] and Gheisari et al. proved that boriding increases wear resistance of nickel alloys in elevated temperatures as well [24]. Diffusion boriding of Monel 400 surface was performed in 2019 and as a result of this process both hardness and wear resistance were improved by several times [25].

In this study boriding of Monel 400 was performed with laser boriding process. The main advantages of this method are: obtaining layers of greater thickness than diffusion boriding and a possibility to treat only selected areas instead of whole products. In 1996 Nakata et al. had already reported that laser boriding of $\mathrm{Ni}-\mathrm{Cu}$ alloys (of different proportions of these elements) is an effective method for increasing hardness of their surfaces, and wear resistance was improved up to about 40 times in comparison with the substrate [4]. In 2016, Monel 400 was laser alloyed with nickel, chrome, silicon and boron. This combination of alloying elements led to obtain surface 7 times harder [5]. In 2018 it was found that laser boriding of Monel 400 significantly increases its hardness, but this increase is highly dependent on laser remelting parameters: mainly laser beam power, laser beam scanning velocity and amount of boron in the molten pool [6]. Despite there being no research on wear resistance of laser borided Monel 400, it is worth noting that researchers report improving other metal alloys' wear resistance by alloying surfaces during this process [26-30]. Thus, due to the fact that Monel 400 is highly exposed to wear, the authors decided to investigate this effect on this specific $\mathrm{Ni}-\mathrm{Cu}$ alloy as well. 


\section{Materials and Methods}

\subsection{Materials}

In this experiment, Monel 400 was laser alloyed with boron. Monel 400 is a single-phase nickel-copper alloy and its chemical composition is given in Table 1. Dimensions of specimens prepared for laser treatment were $30 \mathrm{~mm} \times 20 \mathrm{~mm} \times 12 \mathrm{~mm}$. Material was laser alloyed with boron layers $100 \mu \mathrm{m}$ and $200 \mu \mathrm{m}$ thick. Amorphous boron powder was deposited on surfaces of specimens as a paste, after mixing it with sodium water glass. Counterspecimens for wear tests were made from bearing steel 100Cr6. Chemical composition of 100Cr6 steel is given in Table 2. Its hardness is equal to $64 \mathrm{HRC}$, which is approximately $700 \mathrm{HV}$.

Table 1. Chemical composition of Monel 400.

\begin{tabular}{ccccccc}
\hline $\mathrm{Cu}[\%]$ & $\mathrm{Si}[\%]$ & $\mathrm{Fe}[\%]$ & $\mathrm{Mn}[\%]$ & $\mathrm{C}[\%]$ & $\mathrm{S}[\%]$ & $\mathrm{Ni}$ \\
\hline 31 & 0.5 & 2.5 & 2.0 & 0.3 & 0.024 & bal. \\
\hline
\end{tabular}

Table 2. Chemical composition of 100Cr6 bearing steel.

\begin{tabular}{cccccccccc}
\hline C [\%] & Si [\%] & Mn [\%] & Cr [\%] & Mo [\%] & Cu [\%] & Al [\%] & P [\%] & S [\%] & Fe \\
\hline 1.00 & 0.25 & 0.35 & 1.45 & 0.1 & 0.3 & 0.05 & 0.025 & 0.015 & bal. \\
\hline
\end{tabular}

\subsection{Laser Heat Treatment}

Laser heat treatment was performed using diode laser TRUMPF TruDiode 3006 which reaches $3 \mathrm{~kW}$ of power (TRUMPF, Ditzingen, Germany). Laser head was integrated with robot arm KUKA KR16-2 (KUKA, Augsburg, Germany) to manipulate location of the beam. To provide constant laser beam velocity on whole length of laser track, the laser beam was started above and turned off behind the specimen just like in papers [6,31]. The scheme of the laser alloying process is presented in Figure 1.

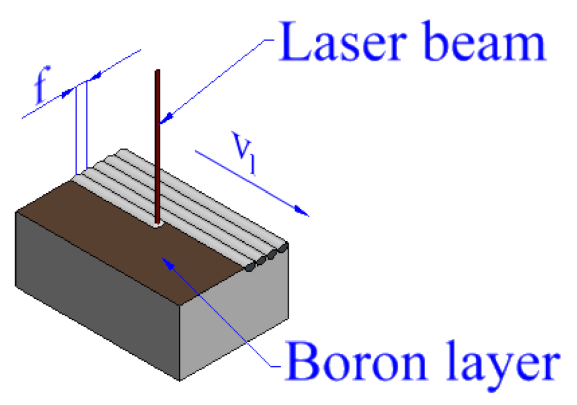

Figure 1. Scheme of the laser boriding process.

During laser alloying of Monel 400 with boron each laser track was produced parallelly to longer side of specimen and distance between tracks (f) was equal to $0.5 \mathrm{~mm}$. Constant laser beam power $\mathrm{P}=1400 \mathrm{~W}$ was used and considering the laser beam diameter was $\mathrm{d}_{1}=1 \mathrm{~mm}$, laser beam power density (q) was equal to $178.3 \mathrm{~kW} / \mathrm{cm}^{2}$. Two laser scanning velocities were set: $5 \mathrm{~m} / \mathrm{min}$ and $50 \mathrm{~m} / \mathrm{min}$. Laser heat treatment was performed on two different types of specimens: Monel 400 with initial boron layer of thickness equal to $t_{b}=100 \mu \mathrm{m}$ and Monel 400 with boron layer of thickness equal to $t_{b}=200 \mu \mathrm{m}$. These parameters are collected in Table 3. The specimen marked with symbol "E" stands for untreated Monel 400. 
Table 3. Laser alloying parameters.

\begin{tabular}{ccccccc}
\hline $\mathbf{P}[\mathbf{W}]$ & $\mathbf{q}\left[\mathbf{k W} / \mathbf{c m}^{2}\right]$ & $\mathbf{t}_{\mathbf{b}}[\boldsymbol{\mu m}]$ & $\mathbf{v}_{\mathbf{l}}[\mathbf{m} / \mathbf{m i n}]$ & $\mathbf{d}_{\mathbf{l}}[\mathbf{m m}]$ & $\mathbf{f}[\mathbf{m m}]$ & Symbol of Specimen \\
\hline 1400 & 178.3 & 100 & 5 & 1 & 0.5 & $\mathrm{~A}$ \\
1400 & 178.3 & 200 & 5 & 1 & 0.5 & $\mathrm{~B}$ \\
1400 & 178.3 & 100 & 50 & 1 & 0.5 & $\mathrm{C}$ \\
1400 & 178.3 & 200 & 50 & 1 & 0.5 & $\mathrm{D}$ \\
- & - & - & - & - & - & $\mathrm{E}$ \\
\hline
\end{tabular}

\subsection{Samples Preparation}

After laser alloying, samples were cut for obtaining specimens for the wear test (with dimensions $13 \mathrm{~mm} \times 10 \mathrm{~mm} \times 6 \mathrm{~mm}$ ). For comparison of the wear resistance, one additional specimen made from untreated Monel 400 was also prepared. Other pieces of borided samples were cut across laser tracks for obtaining metallographic microsections. Cutting was performed using hand saw blade to reduce any structural changes. Samples designed for wear test were slightly grinded to obtain Ra lower than $0.2 \mu \mathrm{m}$. Cross-sections of specimens designed for structural investigation were grinded with abrasive papers of grits ranged from 120 to 2000. Thereafter, they were polished for $20 \mathrm{~min}$ and etched with Marble's reagent.

\subsection{Microstructure and Chemical Composition}

Microstructural investigation of laser borided layers' cross-sections, as well as surfaces after wear tests was carried out using scanning electron microscope Tescan MIRA3 (TESCAN, Brno, Czech Republic). This instrument was equipped with Oxford Instruments EDS (Energy-dispersive X-ray spectroscopy) detector (Oxford Instruments, High Wycombe, UK) with AZtec system version 4.2 , which were used for chemical composition analysis.

\subsection{Microhardness Testing}

Microhardness indentations were fabricated with Zwick 3212B Vickers tester (Zwick, Ulm, Germany) with constant load equal to $0.9807 \mathrm{~N}$. Load was kept on samples for $15 \mathrm{~s}$ for each indentation. On each sample, indentations were made in different distances from surfaces, and five indentations were fabricated in the substrate.

\subsection{Wear Test}

Specimens cut to dimensions suitable for the wear tester were mounted in it in a way presented in Figure 2. Machine used for the testing was AMSLER A135 (Amsler, Szafuza, Switzerland) which allows to set specific load to the specimen and specific rotational speed to the counterspecimen. Dimensions of the counterspecimen were $45 \mathrm{~mm}$ in diameter and thickness equal to $12 \mathrm{~mm}$, with mounting hole of diameter equal to $15 \mathrm{~mm}$. In this study load was equal to $\mathrm{F}=392 \mathrm{~N}$ and rotational speed of the counterspecimen $\mathrm{n}=180 \mathrm{rev} . / \mathrm{min}$, just like at paper [32]. Some droplets of water were delivered to the friction zone to make the friction coefficient lower. During the process, two temperatures (T1 and T2) were measured using thermometer TES-1312A (TES, Taipei, Taiwan) with probe equipped with thermocouple type "K"-NiCr-NiAl. Places of these measurements are presented in Figure 2. Measurements of temperature T1 were taken from inside the sample through a drilled hole and temperature T2 was measured on surfaces of counterspecimens, just behind the friction zone. Moreover, frictional moments were measured for each specimen during the process. Testing time of boron-alloyed specimens was equal to $t=45 \mathrm{~min}$. The wear test of sample made from Monel 400 was stopped after $5 \mathrm{~min}$ due to the fact that the specimen suffered notable seizing and large increases in temperatures $\mathrm{T} 1$ and $\mathrm{T} 2$ was observed. 


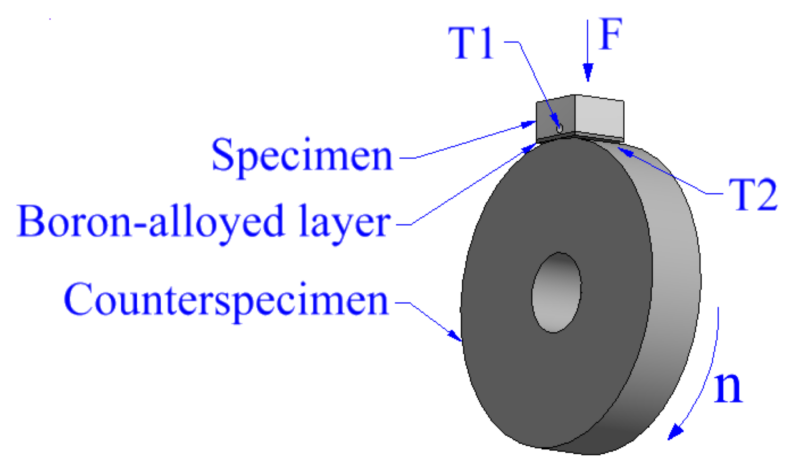

Figure 2. Scheme of the wear test.

\subsection{Depth of Friction Zone and Mass Loss}

For measuring depth of friction zone, contact profilometer ZEISS (Carl Zeiss, Oberkochen, Germany) was used. It was equipped with induction converter and SUFORM software version 2.0 provided by SAJD Metrologia company (SAJD, Kielce, Poland). Measuring the mass loss of specimens after the wear test was performed with laboratory weight Sartorius BP221S (PCE-instruments, Southampton, Hampshire, UK) with a precision of $0.0001 \mathrm{~g}$.

\section{Results and Discussion}

\subsection{Microstructural Characterization and Microhardness}

Microstructures of laser alloyed surfaces are shown in Figures 3 and 4. Additionally, Figure 3 includes EDS mappings of produced coatings for chemical composition analysis. Each of these figures presents surfaces treated with two different laser beam scanning velocities and two different thicknesses of initial boron layer. Letters which are given within figures indicate following process parameters: (a) laser beam scanning velocity $\mathrm{v}_{\mathrm{l}}=5 \mathrm{~m} / \mathrm{min}$ and initial boron layer thickness $\mathrm{t}_{\mathrm{b}}=100 \mu \mathrm{m}$, (b) $\mathrm{v}_{\mathrm{l}}=5 \mathrm{~m} / \mathrm{min}$ and $\mathrm{t}_{\mathrm{b}}=200 \mu \mathrm{m},(\mathrm{c}) \mathrm{v}_{\mathrm{l}}=50 \mathrm{~m} / \mathrm{min}$ and $\mathrm{t}_{\mathrm{b}}=100 \mu \mathrm{m},(\mathrm{d}) \mathrm{v}_{\mathrm{l}}=50 \mathrm{~m} / \mathrm{min}$ and $\mathrm{t}_{\mathrm{b}}=200 \mu \mathrm{m}$.

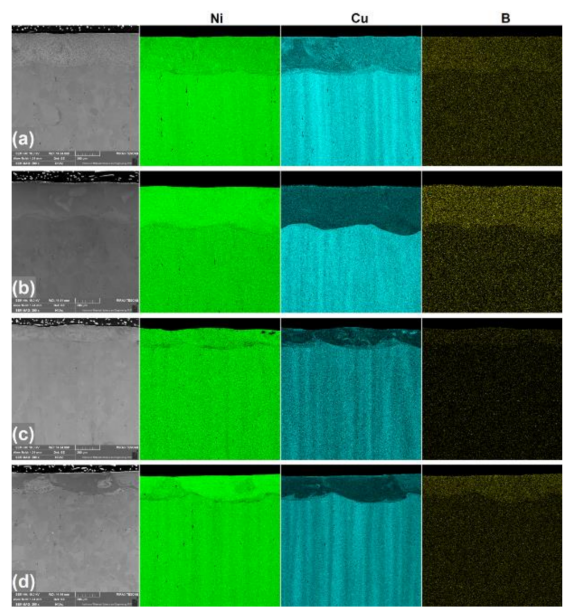

Figure 3. Laser borided layers produced on Monel 400 with different parameters with their EDS mappings: (a) $\mathrm{v}_{\mathrm{l}}=5 \mathrm{~m} / \mathrm{min}$ and $\mathrm{t}_{\mathrm{b}}=100 \mu \mathrm{m},(\mathbf{b}) \mathrm{v}_{\mathrm{l}}=5 \mathrm{~m} / \mathrm{min}$ and $\mathrm{t}_{\mathrm{b}}=200 \mu \mathrm{m},(\mathbf{c}) \mathrm{v}_{\mathrm{l}}=50 \mathrm{~m} / \mathrm{min}$ and $\mathrm{t}_{\mathrm{b}}=100 \mu \mathrm{m},(\mathbf{d}) \mathrm{v}_{\mathrm{l}}=50 \mathrm{~m} / \mathrm{min}$ and $\mathrm{t}_{\mathrm{b}}=200 \mu \mathrm{m}$. 

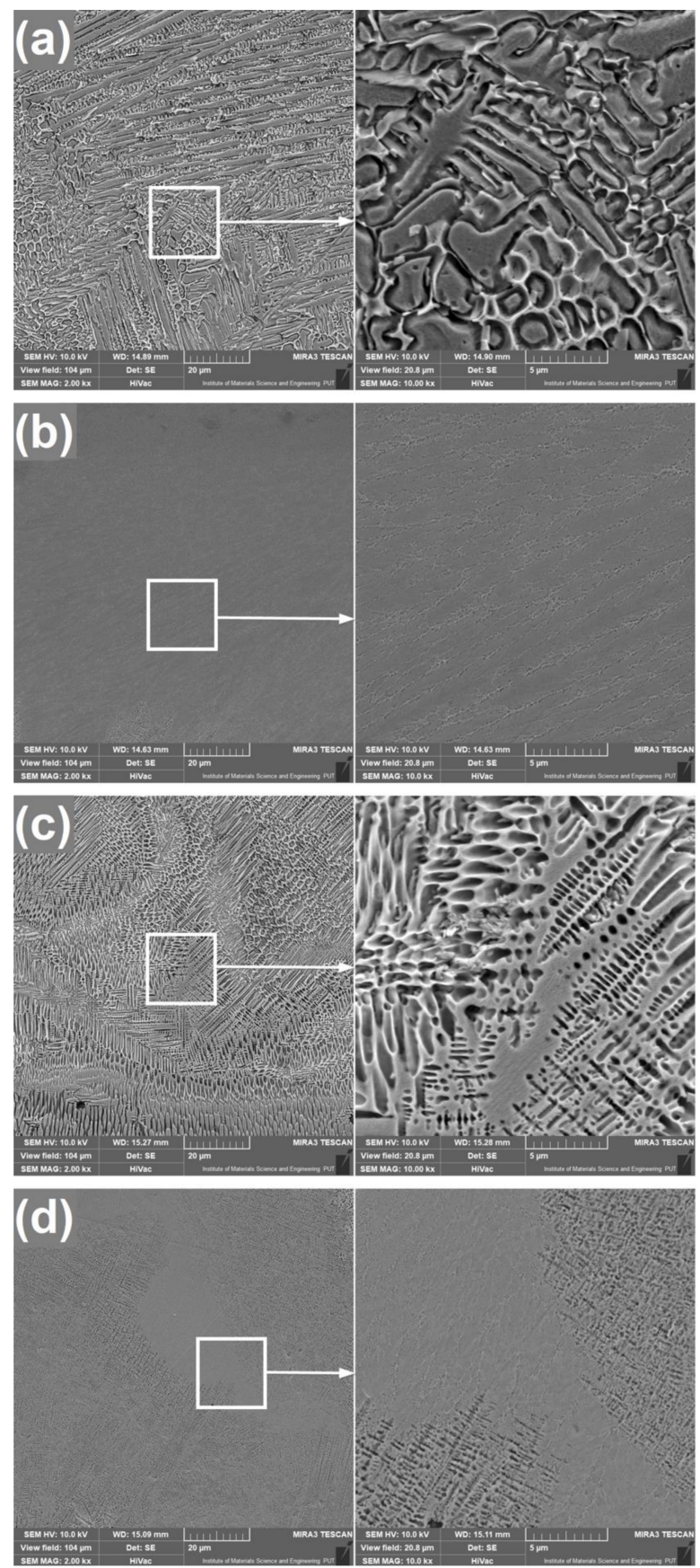

Figure 4. Microstructures of laser borided layers produced on Monel 400 with different parameters: (a) $\mathrm{v}_{\mathrm{l}}=5 \mathrm{~m} / \mathrm{min}$ and $\mathrm{t}_{\mathrm{b}}=100 \mu \mathrm{m},(\mathbf{b}) \mathrm{v}_{\mathrm{l}}=5 \mathrm{~m} / \mathrm{min}$ and $\mathrm{t}_{\mathrm{b}}=200 \mu \mathrm{m},(\mathbf{c}) \mathrm{v}_{\mathrm{l}}=50 \mathrm{~m} / \mathrm{min}$ and $\mathrm{t}_{\mathrm{b}}=100 \mu \mathrm{m}$, (d) $\mathrm{v}_{\mathrm{l}}=50 \mathrm{~m} / \mathrm{min}$ and $\mathrm{t}_{\mathrm{b}}=200 \mu \mathrm{m}$.

It is clearly seen that laser re-melting of Monel 400 with boron has a significant influence on its microstructure. However, microstructures of layers with different initial boron thicknesses differ more from each other than layers produced with different laser beam scanning velocities. Layers alloyed with boron paste $100 \mu \mathrm{m}$ thick, which are shown in Figures $3 \mathrm{a}, \mathrm{c}$ and $4 \mathrm{a}, \mathrm{c}$ are built mainly of column crystals solidified in much directions which depend on turbulences of liquid metal during re-melting. Grains can be seen as lengthy or as equiaxed due to the fact that some of their crystallization fronts were directed parallel to the laser movement and it can be especially seen in Figure 4a. According to Safonov et al. [27], laser alloyed layers which include low amount of boron crystalize into structures of primary dendrites and a boride eutectic between them. It is considered that layer produced with 
$\mathrm{v}_{\mathrm{l}}=5 \mathrm{~m} / \mathrm{min}$ is built of hypoeutectic and layer produced with $\mathrm{v}_{\mathrm{l}}=50 \mathrm{~m} / \mathrm{min}$ is eutectic, because of higher concentration of boron in the re-melted volume. Moreover, it can be seen with high magnification in Figure $4 \mathrm{a}, \mathrm{c}$ that sizes of grains are strongly dependent on laser beam scanning velocity. Column crystals emerged on specimen treated with $\mathrm{v}_{\mathrm{l}}=5 \mathrm{~m} / \mathrm{min}$ are visibly few times larger than these obtained during alloying with $\mathrm{v}_{\mathrm{l}}=50 \mathrm{~m} / \mathrm{min}$. This effect is the result of grain growth during long time of exposition to laser radiation on specimens produced with $\mathrm{v}_{\mathrm{l}}=5 \mathrm{~m} / \mathrm{min}$ and quick solidification of layers produced with $\mathrm{v}_{1}=50 \mathrm{~m} / \mathrm{min}$. On the other hand, microstructures of surfaces which were alloyed with initial boron layer thickness equal to $200 \mu \mathrm{m}$ are more uniform. Safonov et al. [27] concluded that microstructures laser alloyed with high amount of boron consist of primary boride crystals and a eutectic. In this study, these layers, in most of their volume, seem like solid one-phase materials which is a hypereutectic structure. However, in both cases there are noticeable areas of various tints in which chemical compositions and crystal orientations differ from other volume. Their presence is the result of insufficient mixing of substrates in the molten pool. This effect can be observed in EDS mappings presented in Figure 3. Although boron is distributed uniformly within produced coatings, concentrations of nickel and copper vary in different areas. Moreover, since the mixing is weaker in layers produced with higher laser beam scanning velocity (Figure 3c,d), these areas differ more from surrounding volume than in specimens produced with $\mathrm{v}_{1}=5 \mathrm{~m} / \mathrm{min}$. This suggests that, due to insufficient mixing in coatings produced with $\mathrm{v}_{\mathrm{l}}=50 \mathrm{~m} / \mathrm{min}$, the microstructure is built of both hypereutectic and eutectic areas. Furthermore, it is worth noting that in both layers produced with $200 \mu \mathrm{m}$ initial boron layer structure built of columnar crystals is visible between re-melted zone and the substrate.

Microstructures of layers alloyed with boron using different laser beam scanning velocities do not differ as significantly as if boron content is considered. However, the main difference between them is their depth. In this experiment depths of boron-alloyed layers were measured ten times for each specimen. Average depths of coatings produced using laser beam scanning velocity $v_{l}=5 \mathrm{~m} / \mathrm{min}$ are equal to approximately $300 \mu \mathrm{m}$ and $410 \mu \mathrm{m}$ if initial boron layer thickness was $100 \mu \mathrm{m}$ and $200 \mu \mathrm{m}$ respectively. Increasing laser beam scanning velocity to $50 \mathrm{~m} / \mathrm{min}$ results in obtaining layers enriched with boron approximately $130 \mu \mathrm{m}$ and $175 \mu \mathrm{m}$ deep. Both laser beam scanning velocity and initial boron layer thickness affect the depth of re-melting. The higher laser beam scanning velocity is, the shallower alloyed layer is. It is the result of shorter time of influence of laser radiation on material's surface during the process. On the other hand, the more boron is provided in the molten pool, the deeper the layer that is obtained. This effect is considered to be caused by higher thermal conductivity of nickel borides than of Monel 400.

Microhardness of untreated Monel 400 is ranged between 150 and 200 HV0.1. It was confirmed that alloying Monel 400 with boron increases these values significantly. In this study, as in case of depth, final results depend on laser beam scanning velocity and thickness of initial boron layer. In this study microhardness was measured in two different laser tracks. Average values of microhardness, depending on distance from surface, are presented in Figure 5. Laser alloying with initial boron layer $100 \mu \mathrm{m}$ thick using laser beam scanning velocity equal to $5 \mathrm{~m} / \mathrm{min}$ resulted in obtaining almost two times harder surface layer (between 280 and 310 HV0.1). Increasing boron content to initial layer thickness equal to $200 \mu \mathrm{m}$ leads to obtain layer of microhardness between 870 and $930 \mathrm{HV} 01$. Due to the fact that increasing laser beam scanning velocity results in decreasing depths of obtained layers, microhardness of surfaces alloyed with boron using $\mathrm{v}_{\mathrm{l}}=50 \mathrm{~m} / \mathrm{min}$ is higher with the same initial boron content. The reason for this is higher concentration of hard nickel borides in smaller re-melted volume of material. Thus, microhardness of layer enriched with $100 \mu \mathrm{m}$ of boron paste ranged between 400 and $450 \mathrm{HV} 0.1$ if the laser beam scanning velocity is equal to $50 \mathrm{~m} / \mathrm{min}$. Doubling the initial boron content to $200 \mu \mathrm{m}$ results in obtaining microhardness from 890 to 1000 HV0.1. Taking into consideration that surfaces treated with higher laser beam scanning velocity are built of smaller grains, their higher microhardness increase could also be affected by the higher number of grain boundaries present in re-melted zones. 

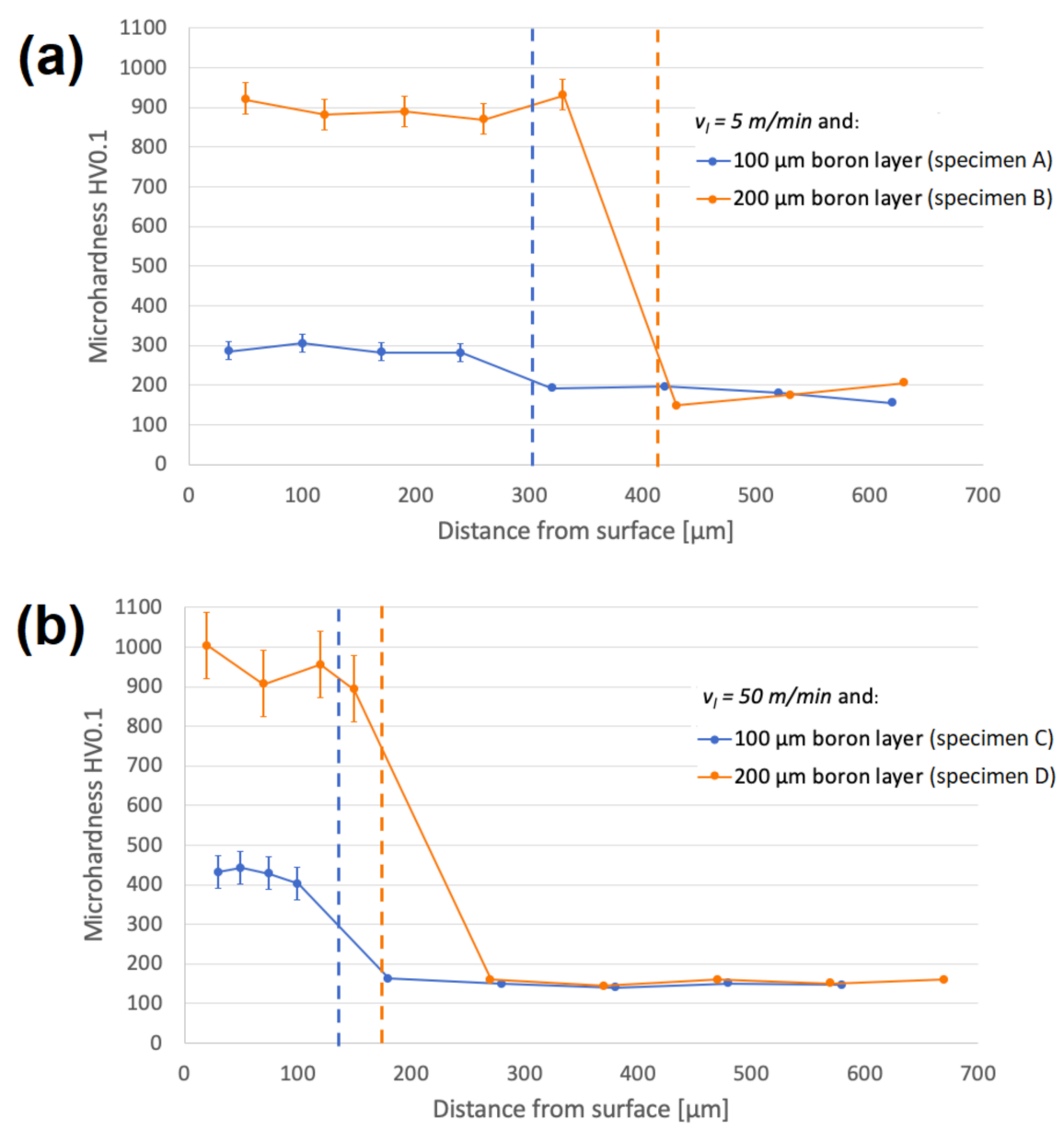

Figure 5. Microhardness of borided layers in different distances from surface, alloyed with: (a) $\mathrm{v}_{1}=5 \mathrm{~m} / \mathrm{min}$ and $(\mathbf{b}) \mathrm{v}_{1}=50 \mathrm{~m} / \mathrm{min}$.

\subsection{Wear Analysis}

For quantitative comparison of wear resistance of laser borided Monel 400 surfaces, two indicators were taken into consideration: depth of the friction zone and mass loss of each specimen after the wear test. In Figure 6, an exemplary measurement of depth of friction zone is shown. This specific profile was measured on sample borided with $100 \mu \mathrm{m}$ boron paste using laser beam scanning velocity equal to $50 \mathrm{~m} / \mathrm{min}$. Figure 7 is a graphic representation of values of friction zones' depths and mass losses after the wear test.

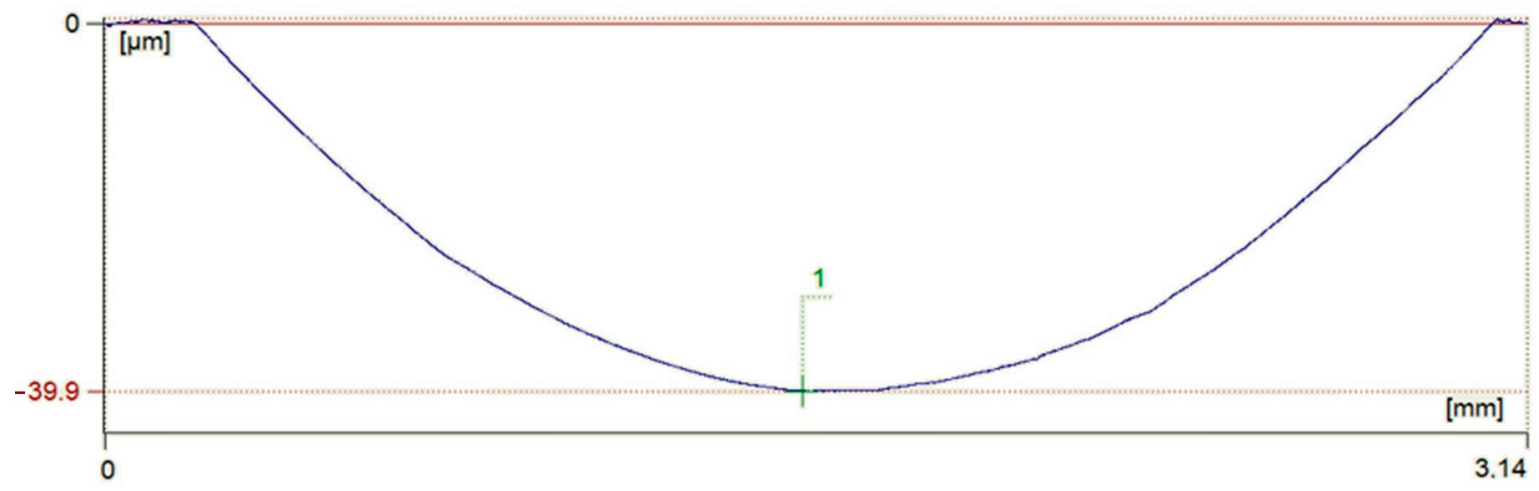

Figure 6. Measurement of depth of friction zone on specimen laser borided with $\mathrm{v}_{l}=50 \mathrm{~m} / \mathrm{min}$ and $\mathrm{t}_{\mathrm{b}}=100 \mu \mathrm{m}$. 


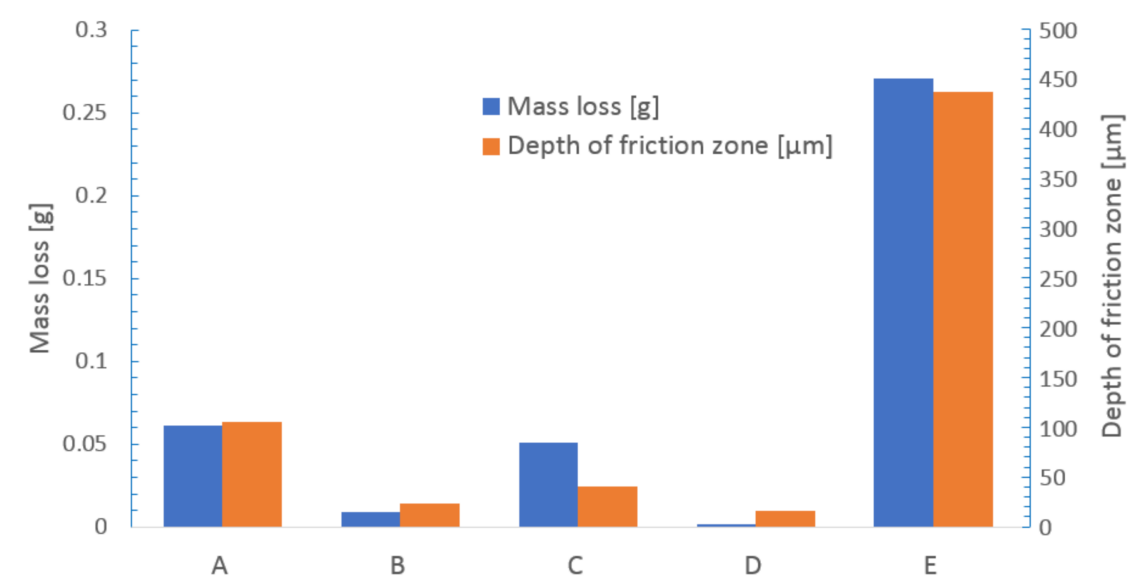

Figure 7. Mass losses and depths of friction zones of specimens after the wear test.

It was found that the rate of wear is strongly dependent on microhardness. The shallowest friction zone after the wear test was measured on sample laser alloyed with $200 \mu \mathrm{m}$ boron paste using laser beam scanning velocity equal to $\mathrm{v}_{1}=50 \mathrm{~m} / \mathrm{min}$. In this case, the depth of friction zone was equal to $15.8 \mu \mathrm{m}$. The second lowest value, equal to $23.7 \mu \mathrm{m}$, was measured on sample which was prepared with the same boron content but with lower laser beam scanning velocity $\mathrm{v}_{\mathrm{l}}=5 \mathrm{~m} / \mathrm{min}$. Samples produced with initial boron layers $100 \mu \mathrm{m}$ thick suffered wear which resulted in obtaining friction zones $39.9 \mu \mathrm{m}$ and $105.5 \mu \mathrm{m}$ deep on samples alloyed using laser beam scanning velocity equal to $50 \mathrm{~m} / \mathrm{min}$ and $5 \mathrm{~m} / \mathrm{min}$ respectively. For comparison, depth of friction zone on untreated Monel 400 was equal to $436.5 \mu \mathrm{m}$ after only $5 \mathrm{~min}$ of wear test. These numbers confirm that laser alloying of Monel 400 surface with boron significantly increases its resistance to wear. In terms of differences in depth of the friction zone, the resistance to wear was increased minimum 4-times and maximum 27-times, and even more, if the fact that sample of untreated Monel 400 was tested for 9-times shorter period of time is taken into consideration.

Values of mass loss after the wear test are convergent with these described above. The lowest mass loss, measured on specimen laser alloyed with $200 \mu \mathrm{m}$ boron paste and $\mathrm{v}_{\mathrm{l}}=50 \mathrm{~m} / \mathrm{min}$, was equal to $0.0013 \mathrm{~g}$ after $45 \mathrm{~min}$ of testing. Mass loss of sample re-melted with same boron content but slower laser beam scanning velocity $\mathrm{v}_{1}=5 \mathrm{~m} / \mathrm{min}$ was equal to $0.009 \mathrm{~g}$. Mass loss, as well as depth of friction zone, was greater if initial boron layer thickness was equal to $100 \mu \mathrm{m}$. In these cases, masses of specimens decreased by $0.0511 \mathrm{~g}$ if laser beam scanning velocity $\mathrm{v}_{\mathrm{l}}=50 \mathrm{~m} / \mathrm{min}$ and $0.0611 \mathrm{~g}$ if $\mathrm{v}_{\mathrm{l}}=5 \mathrm{~m} / \mathrm{min}$ was used for the boron-alloying process. Mass loss of untreated Monel 400 was equal to $0.2707 \mathrm{~g}$ after $5 \mathrm{~min}$ of testing. These values indicate even greater increase in wear resistance than values of friction zones' depths. The lowest measured value of mass loss, on specimen tested for $45 \mathrm{~min}$, is more than 200-times lower than mass reduction of Monel 400 sample after 5 min of the wear test. On the other hand, quadrupled increase in wear resistance of surface alloyed with $100 \mu \mathrm{m}$ of boron paste and laser beam scanning velocity equal to $5 \mathrm{~m} / \mathrm{min}$, in terms of mass loss, is comparable with the result obtained by analysis of depths of friction zones. Nonetheless, these results clearly indicate that laser alloying Monel 400 with boron significantly enhances wear resistance of the material's surface.

For qualitative assessment of surfaces after the wear test, microscopic examination using scanning electron microscope was performed as well as chemical composition analysis. Results of these observations are given in Figures 8 and 9. In each figure sliding direction is vertical. EDS mappings were taken from the same areas as corresponding photos in Figure 8. Red dots present in Figure 8 represent spots analyzed in terms of chemical composition and their results are given in Table 4. Letters given in Figures 8 and 9 indicate specimens as in Table 3. Analysis of chemical composition, both for points and mappings, was limited to four elements: nickel, copper, iron and oxygen, because verification of their presence is sufficient for the assessment of the nature of wear. Results shown in bold font in Table 4 represent spots of increased content of iron or oxygen. Moreover, for better understanding of 
wear mechanisms which occurred between specimens and counterspecimens, a schematic view of phenomena in wear zones is shown in Figure 10.
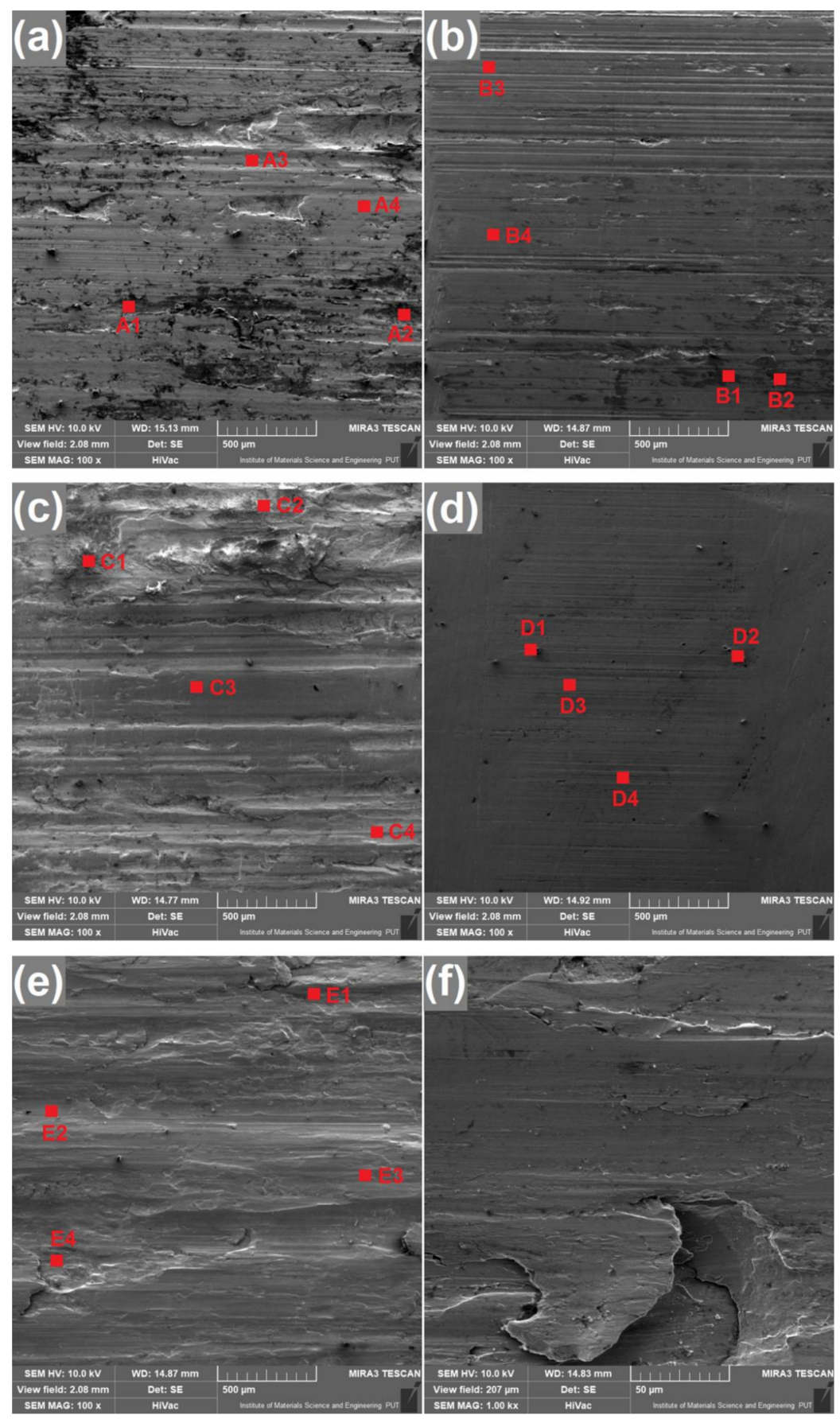

Figure 8. Surfaces after the wear test of specimens produced with: (a) $\mathrm{v}_{\mathrm{l}}=5 \mathrm{~m} / \mathrm{min}$ and $\mathrm{t}_{\mathrm{b}}=100 \mu \mathrm{m}$, (b) $\mathrm{v}_{\mathrm{l}}=5 \mathrm{~m} / \mathrm{min}$ and $\mathrm{t}_{\mathrm{b}}=200 \mu \mathrm{m},(\mathbf{c}) \mathrm{v}_{\mathrm{l}}=50 \mathrm{~m} / \mathrm{min}$ and $\mathrm{t}_{\mathrm{b}}=100 \mu \mathrm{m},(\mathbf{d}) \mathrm{v}_{\mathrm{l}}=50 \mathrm{~m} / \mathrm{min}$ and $\mathrm{t}_{\mathrm{b}}=200 \mu \mathrm{m}$, (e,f) untreated Monel 400. 


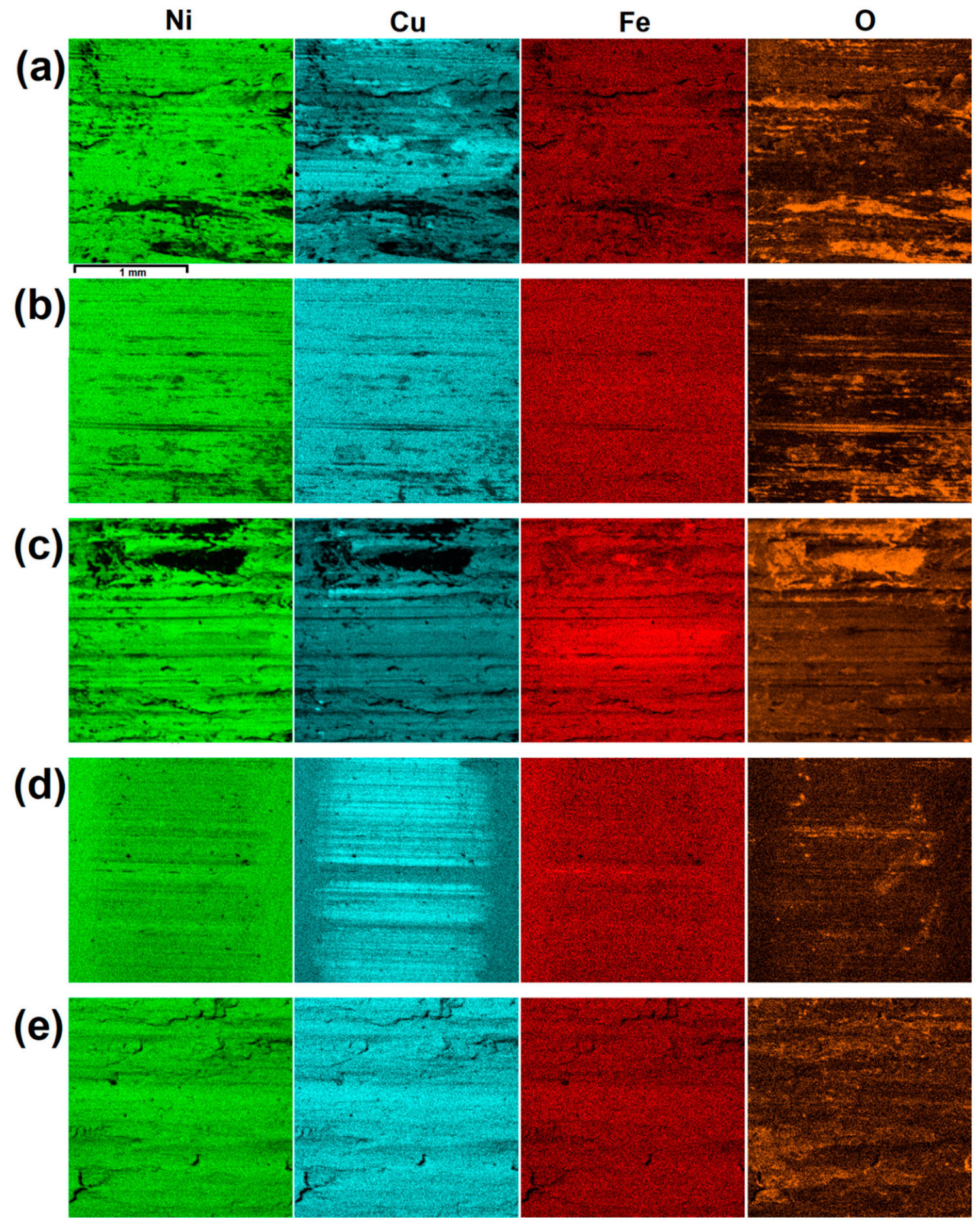

Figure 9. EDS mappings of surfaces after the wear test: (a) $\mathrm{v}_{\mathrm{l}}=5 \mathrm{~m} / \mathrm{min}$ and $\mathrm{t}_{\mathrm{b}}=100 \mu \mathrm{m},(\mathbf{b}) \mathrm{v}_{\mathrm{l}}=5 \mathrm{~m} / \mathrm{min}$ and $t_{b}=200 \mu \mathrm{m},(\mathbf{c}) \mathrm{v}_{\mathrm{l}}=50 \mathrm{~m} / \mathrm{min}$ and $\mathrm{t}_{\mathrm{b}}=100 \mu \mathrm{m},(\mathbf{d}) \mathrm{v}_{\mathrm{l}}=50 \mathrm{~m} / \mathrm{min}$ and $\mathrm{t}_{\mathrm{b}}=200 \mu \mathrm{m},(\mathbf{e})$ untreated Monel 400. 
Table 4. Results of chemical composition analysis of spots marked in Figure 8.

\begin{tabular}{ccccccccccc}
\hline Symbol & A1 & A2 & A3 & A4 & B1 & B2 & B3 & B4 & C1 & C2 \\
\hline $\mathrm{Ni}[\mathrm{Wt} \%]$ & $\mathbf{3 0 . 4}$ & $\mathbf{2 6 . 9}$ & 59.7 & 42.9 & $\mathbf{3 7 . 1}$ & $\mathbf{3 8 . 1}$ & 57.0 & 58.2 & $\mathbf{1 9 . 3}$ & $\mathbf{1 9 . 9}$ \\
$\mathrm{Cu}[\mathrm{Wt} \%]$ & $\mathbf{1 8 . 2}$ & $\mathbf{1 6 . 9}$ & 35.3 & 53.4 & $\mathbf{7 . 6}$ & $\mathbf{7 . 3}$ & 33.9 & 33.0 & $\mathbf{1 6 . 4}$ & $\mathbf{0 . 8}$ \\
$\mathrm{Fe}[\mathrm{Wt} \%]$ & $\mathbf{2 0 . 1}$ & $\mathbf{2 1 . 6}$ & 3.1 & 2.2 & $\mathbf{2 8 . 7}$ & $\mathbf{2 6 . 9}$ & 6.4 & 6.5 & $\mathbf{2 5 . 6}$ & $\mathbf{4 4 . 7}$ \\
$\mathrm{O}[\mathrm{Wt} \%]$ & $\mathbf{3 1 . 3}$ & $\mathbf{3 4 . 7}$ & 1.8 & 1.5 & $\mathbf{2 6 . 6}$ & $\mathbf{2 7 . 7}$ & 2.3 & 2.2 & $\mathbf{3 8 . 8}$ & $\mathbf{3 4 . 6}$ \\
\hline $\mathrm{Symbol}$ & $\mathbf{C 3}$ & $\mathbf{C 4}$ & $\mathbf{D 1}$ & $\mathbf{D 2}$ & $\mathbf{D 3}$ & $\mathbf{D 4}$ & $\mathbf{E 1}$ & $\mathbf{E 2}$ & $\mathbf{E 3}$ & E4 \\
\hline $\mathrm{Ni}[\mathrm{Wt} \%]$ & 58.3 & 59.9 & $\mathbf{4 9 . 4}$ & $\mathbf{4 1 . 3}$ & 60.5 & 62.7 & 61.1 & 63.2 & 64.1 & 63.5 \\
$\mathrm{Cu}[\mathrm{Wt} \%]$ & 30.0 & 32.2 & $\mathbf{2 3 . 3}$ & $\mathbf{4 5 . 0}$ & 36.0 & 34.0 & 33.1 & 33.7 & 30.7 & 31.5 \\
$\mathrm{Fe}[\mathrm{Wt} \%]$ & 8.4 & 3.7 & $\mathbf{4 . 6}$ & $\mathbf{1 . 8}$ & 2.1 & 2.3 & 2.7 & 2.4 & 4.0 & 2.2 \\
$\mathrm{O}[\mathrm{Wt} \%]$ & 3.4 & 4.1 & $\mathbf{2 2 . 6}$ & $\mathbf{1 1 . 9}$ & 1.4 & 1.0 & 3.1 & 0.7 & 1.3 & 2.8 \\
\hline
\end{tabular}

(a)

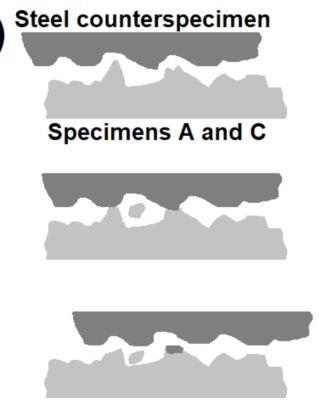

(b)

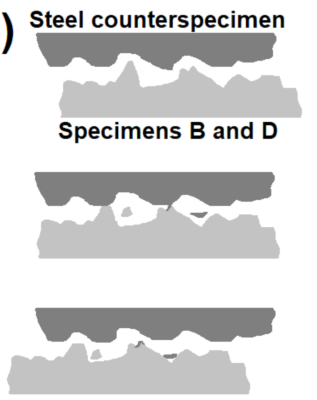

(c)

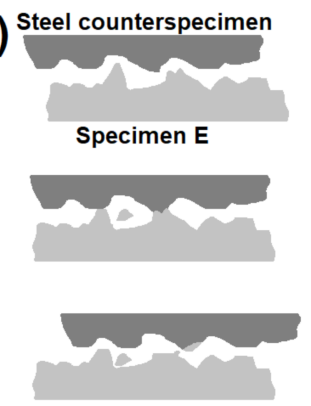

Figure 10. Schemes of wear mechanisms on different specimens: (a) Specimens A and C: serious abrasive wear of the specimen and adhesive wear of the counterspecimen, (b) Specimens B and D: minor abrasive wear of the specimen and adhesive wear of the counterspecimen, (c) Specimen E: serious abrasive and adhesive wear of the specimen, with plastic deformation.

After the wear test, surfaces laser alloyed with boron paste $100 \mu \mathrm{m}$ thick (Figure 8a,c) differ from these which were laser alloyed with higher boron content. Surface presented in Figure 8a which was produced using laser beam scanning velocity equal to $5 \mathrm{~m} / \mathrm{min}$ contains much irregularities after the wear test. Moreover, in pits and built-ups visible on the surface, an increased amount of iron and oxygen was spotted and results of this analysis are given in Table 4 as symbols A1 and A2. The confirmation of this effect is shown in Figure 9a-areas which are darker in Figure 8a contains less nickel and copper but more oxygen than surrounding zones. Taking into consideration chemical composition of Monel 400 alloy and 100Cr6 steel, it is considered that detected fragments is iron detached from counterspecimen, which reacted with oxygen during the wear test. Presence of grooves and iron particles on surface presented in Figure 8a suggests that this surface suffered serious abrasive wear. Surface which was alloyed with the same boron content but higher laser beam scanning velocity that is presented in Figure 8c appears similar after the wear test. However, in this case there are fewer built-ups including iron and oxygen which are visible in Figure $9 \mathrm{c}$ and in spots with symbols $\mathrm{C} 1$ and C2. On the other hand, more wide scratches were found. This suggests that higher hardness resulted in reducing tendency to adhere iron particles from counterspecimen and wear mechanism became more abrasive than adhesive. Schematic representation of wear mechanism of specimens alloyed with $100 \mu \mathrm{m}$ - thick boron paste is shown in Figure 10a.

It is clearly seen in Figure 8b,d that specimens which were alloyed with boron paste $200 \mu \mathrm{m}$ thick suffered minor wear in comparison with these described above. Both surfaces contain much fewer grooves and signs of plastic deformation. Surface presented in Figure $8 \mathrm{~b}$ is mostly covered with scratches of various widths but there are considerably fewer deformed areas than on surfaces alloyed with $100 \mu \mathrm{m}$ boron paste. Despite this, iron particles were detected on this surface as well but in a smaller amount which can be seen in Figure 8b and in results from spots marked as B1 and B2. These results lead to the conclusion that in this case the major mechanism of wear was abrasive. However, presence of iron built-ups detected during analysis of chemical composition suggests that 
slight adhesive wear also occurred in some areas. Moreover, an exemplary graph of frictional moment and temperatures during the wear test of specimen laser alloyed with $200 \mu \mathrm{m}$ boron paste and laser beam scanning velocity equal to $5 \mathrm{~m} / \mathrm{min}$ (Figure 11) indicates irregular movement resistance. On the other hand, a specimen produced with the same amount of boron but higher laser beam scanning velocity which surface is presented in Figure $8 \mathrm{~d}$. This suffered only insignificant wear in comparison with other samples. Scratches visible after the wear test are shallow and narrow, and there are no signs of plastic deformation of alloyed layer. Foreign particles are visible but only as spots (not surfaces like on other specimens) and in small amount. These spots of increased oxygen concentration are visible in Figure 9d, and results of their chemical composition analysis are shown in Table 4 as D1 and D2. This suggests that laser alloyed layer with the highest microhardness suffered only minor abrasive wear, with insignificant share of adhesive wear and oxidation. The scheme of this wear mechanism is shown in Figure 10b.

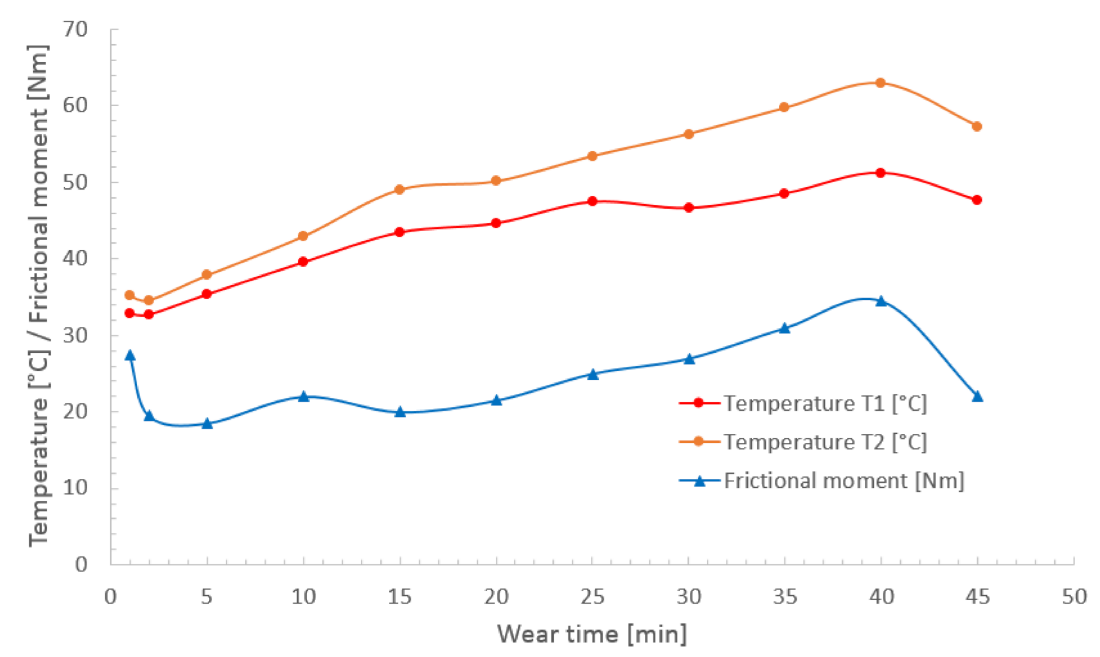

Figure 11. Frictional moment and temperatures $\mathrm{T} 1$ and $\mathrm{T} 2$ as function of wear time for specimen laser borided with laser beam scanning velocity $\mathrm{v}_{\mathrm{l}}=50 \mathrm{~m} / \mathrm{min}$ and initial boron layer $\mathrm{t}_{\mathrm{b}}=100 \mu \mathrm{m}$.

Finally, it is worth noting that although surface of untreated Monel 400 suffered the most serious plastic deformation during the wear test, areas with increased iron concentration were not detected on its surface. It is proven with results shown in Figure 9e and spots marked as E1-E4 in Table 4. In this case, only minor oxidation distributed uniformly was detected. The reason of these effects is lower hardness of Monel 400 itself than hardness of the steel counterspecimen. It is considered that in this case material was detached from the Monel 400 specimen. An example of area of plastic deformation which could occur as a result of detachment of material from Monel 400 surface is given in Figure $8 \mathrm{f}$ with higher magnification. The condition of Monel 400 surface after the wear test ongoing for only $5 \mathrm{~min}$, in comparison with other specimens which were tested for 9 times longer period of time, is a notable evidence that laser alloying with boron is an effective method for increasing wear properties of this nickel-copper alloy. This wear mechanism is shown schematically in Figure 10c.

\section{Conclusions}

On the basis of results and examination of condition of laser borided Monel 400 after wear tests following conclusions were formulated:

(1) Laser alloying with boron is an effective method for improving wear resistance of Monel 400 and level of this enhancement is strongly dependent on microhardness of obtained layers and hence on the laser boriding parameters. This fact confirms that laser boriding can be implemented to increase hardness and wear properties of this specific $\mathrm{Ni}-\mathrm{Cu}$ alloy, as it is for other nickel-based metals. 
(2) Wear resistance, both in terms of depth of friction zone and mass loss after the wear test, improves with increasing initial boron content and laser beam scanning velocity during the laser boriding process. In this study, the highest wear resistance was observed for surface alloyed with initial boron layer $200 \mu \mathrm{m}$ thick using laser beam scanning velocity equal to $50 \mathrm{~m} / \mathrm{min}$.

(3) The improvement of wear resistance achieved by laser alloying Monel 400 with boron is quantitatively larger than increase of microhardness in each examined case. For example, microhardness of surface laser borided with $100 \mu \mathrm{m}$ thick initial boron layer using laser beam scanning velocity equal to $50 \mathrm{~m} / \mathrm{min}$ almost doubles while mass loss during the wear test decreases about five times in comparison with untreated Monel 400.

(4) In conditions chosen for this examination, mechanism of wear evolves from severe abrasive and adhesive on surface alloyed with initial boron layer $100 \mu \mathrm{m}$ thick using laser beam scanning velocity $5 \mathrm{~m} / \mathrm{min}$ to insignificant abrasive wear of surface re-melted with $200 \mu \mathrm{m}$ boron layer and laser beam scanning velocity equal to $50 \mathrm{~m} / \mathrm{min}$. Thus, increasing boron content and laser beam scanning velocity leads to reduction of adhesive wear on alloyed surfaces.

Author Contributions: Conceptualization, M.K., A.B. and D.P.; methodology, M.K., A.B.; investigation, M.K., A.B., D.P. and G.K.; writing - original draft preparation, M.K. and A.B., writing-review and editing, M.K., A.B. and D.P.; visualization, M.K. and A.B. All authors have read and agreed to the published version of the manuscript.

Funding: The presented research results, were funded with grants for education allocated by the ministry of Science and Higher Education in Poland.

Conflicts of Interest: The authors declare no conflict of interest.

\section{References}

1. Hajkowski, J.; Popielarski, P.; Ignaszak, Z. Cellular Automation Finite Element Method Applied for Microstructure Prediction of Aluminium Casting Treated by Laser Beam. Arch. Foundry Eng. 2019, 19, 111-118. [CrossRef]

2. Chwalczuk, T.; Przestacki, D.; Szablewski, P.; Felusiak, A. Microstructure characterisation of Inconel 718 after laser assisted turning. MATEC Web Conf. 2018, 188, 02004. [CrossRef]

3. Przestacki, D.; Kukliński, M.; Bartkowska, A. Influence of laser heat treatment on microstructure and properties of surface layer of Waspaloy aimed for laser-assisted machining. Int. J. Adv. Manuf. Technol. 2017, 93, 3111-3123. [CrossRef]

4. Nakata, K.; Tomoto, K.; Matsuda, F. Laser Boronizing of Copper Alloy. Trans. JWRI 1996, 25, $37-41$.

5. Zhang, C.; Wu, C.; Zhang, S.; Jia, Y.; Guan, M.; Tan, J.; Lin, B. Laser cladding of NiCrSiB on Monel 400 to enhance cavitation erosion and corrosion resistance. Rare Met. 2016, 1-9. [CrossRef]

6. Kukliński, M.; Bartkowska, A.; Przestacki, D. Microstructure and selected properties of Monel 400 alloy after laser heat treatment and laser boriding using diode laser. Int. J. Adv. Manuf. Technol. 2018, 98, 3005-3017. [CrossRef]

7. Żórawski, W.; Chatys, R.; Radek, N.; Borowiecka-Jamrozek, J. Plasma sprayed composite coatings with reduced friction coefficient. Surf. Coat. Technol. 2018, 202, 4578-4582. [CrossRef]

8. High-Performance Alloys for Resistance to Aqueous Corrosion. Available online: http://www.parrinst.com/ wp-content/uploads/downloads/2011/07/Parr_Inconel-Incoloy-Monel-Nickel-Corrosion-Info.pdf (accessed on 16 October 2020).

9. Dutta, R.S. Corrosion aspects of Ni-Cr-Fe based and Ni-Cu based steam generator tube materials. J. Nucl. Mater. 2009, 393, 343-349. [CrossRef]

10. Shoemaker, L.E. A Century of Monel Metal: 1906-2006. JOM 2006, 58, 22-26. [CrossRef]

11. Monel-alloy-400. Available online: http://www.specialmetals.com/assets/smc/documents/alloys/monel/ monel-alloy-400.pdf (accessed on 16 October 2020).

12. Wiciak-Pikuła, M.; Felusiak-Czyryca, A.; Twardowski, P. Tool Wear Prediction Based on Artificial Neural Network during Aluminum Matrix Composite Milling. Sensors 2020, 20, 5798. [CrossRef]

13. Bill, R.C. Study of fretting wear in titanium, monel-400, and cobalt-25 percent molybdenum using scanning electron microscopy. ASLE Trans 1973, 16, 286-290. [CrossRef] 
14. Esgin, U.; Özyürek, D.; Kaya, H. An investigation of wear behaviors of different Monel alloys produced by powder metallurgy. AIP Conf. Proc. 2016, 1727, 020008.

15. Ma, F.; Zeng, Z.; Gao, Y. Tribocorrosion and the surface repassivation behavior of Monel 400 alloy in artificial seawater. Ind. Lubr. Tribol. 2018, 70, 1331-1340. [CrossRef]

16. Waliszyn, A.; Adamkiewicz, A. Studies on resistance to erosion of nickel and its alloys to be used in elements of fluid-flow machines. Eksploatacja i Niezawodnosc 2019, 21, 692-696. [CrossRef]

17. Ueda, N.; Mizukoshi, T.; Demizu, K.; Sone, T.; Ikenaga, A.; Kawamoto, M. Boriding of nickel by the powder-pack method. Surf. Coat. Technol. 2000, 126, 25-30. [CrossRef]

18. Anthymidis, K.G.; Zinoviadis, P.; Roussos, D.; Tsipas, D.N. Boriding of nickel in a fluidized bed reactor. Mater. Res. Bull. 2002, 37, 515-522. [CrossRef]

19. Petrova, R.S.; Suwattananont, N.; Samardzic, V. The Effect of Boronizing on Metallic Alloys for Automotive Applications. J. Mater. Eng. Perform. 2008, 17, 340-345. [CrossRef]

20. Sista, V.; Kahvecioglu, O.; Kartal, G.; Zeng, Q.Z.; Kim, J.H.; Eryilmaz, O.L.; Erdemir, A. Evaluation of electrochemical boriding of Inconel 600. Surf. Coat. Technol. 2013, 215, 452-459. [CrossRef]

21. Gunen, A.; Kanca, E. Microstructure and Mechanical Properties of Borided Inconel 625 Superalloy. Materia 2017, 22, 11829. [CrossRef]

22. Gunen, A.; Kanca, E.; Cakir, H.; Karakas, M.; Gok, M.; Kucuk, Y.; Demir, M. Effect of borotitanizing on microstructure and wear behavior of Inconel 625. Surf. Coat. Technol. 2017, 311, 374-382. [CrossRef]

23. Campos-Silva, I.; Contla-Pacheco, A.D.; Figueroa-López, U.; Martínez-Trinidad, J.; Garduño-Alva, A.; Ortega-Avilés, M. Sliding wear resistance of nickel boride layers on an Inconel 718 superalloy. Surf. Coat. Technol. 2019, 378, 124862. [CrossRef]

24. Gheisari, R.; Polycarpou, A.A. Tribology of Selected Hard Coatings for Oil and Gas Applications Up to $450{ }^{\circ} \mathrm{C}$. Tribol. Lett. 2019, 67, 51. [CrossRef]

25. Krelling, A.P.; Melo, F.S.; Almeida, E.A.S.; Da Costa, C.E.; Milan, J.C.G. Microstructure and properties of borided Monel 400 alloy. Mater. Res. Express 2019, 6, 106410. [CrossRef]

26. Morimoto, J.; Ozaki, T.; Kubohori, T.; Morimoto, S.; Abe, N.; Tsukamoto, M. Some properties of boronized layers on steels with direct diode laser. Vacuum 2009, 83, 185-189. [CrossRef]

27. Safonov, A.N. Special features of boronizing iron and steel using a continuous-wave $\mathrm{CO}_{2}$ laser. Met. Sci. Heat Treat. 1998, 40, 6-10. [CrossRef]

28. Bartkowska, A.; Bartkowski, D.; Popławski, M.; Piasecki, A.; Przestacki, D.; Miklaszewski, A. Microstructure, Microhardness, Corrosion Resistance and Chemical Composition of Mo, B and Mo-B Coatings Produced Using Laser Processing. Materials 2020, 13, 3249. [CrossRef]

29. Tian, Y.S.; Zhang, Q.Y.; Wang, D.Y.; Chen, C.Z. Analysis of the growth morphology of TiB and the microstructure refinement of the coatings fabricated on Ti-6Al-4V by laser boronizing. Cryst. Growth Des. 2008, 8, 700-703. [CrossRef]

30. Kulka, M. Current Trends in Boriding, 1st ed.; Springer: Cham, Switzerland, 2018.

31. Kukliński, M.; Bartkowska, A.; Przestacki, D. Laser Alloying Monel 400 with Amorphous Boron to Obtain Hard Coatings. Materials 2019, 12, 3494. [CrossRef]

32. Bartkowski, D.; Kinal, G. Microstructure and wear resistance of Stellite-6/WC MMC coatings produced by laser cladding using Yb:YAG disk laser. Int. J. Refract. Hard Met. 2016, 58, 157-164. [CrossRef]

Publisher's Note: MDPI stays neutral with regard to jurisdictional claims in published maps and institutional affiliations.

(C) 2020 by the authors. Licensee MDPI, Basel, Switzerland. This article is an open access article distributed under the terms and conditions of the Creative Commons Attribution (CC BY) license (http://creativecommons.org/licenses/by/4.0/). 